ARTICLE

\title{
Brønsted acid sites based on penta-coordinated aluminum species
}

\author{
Zichun Wang ${ }^{1}$, Yijiao Jiang ${ }^{2}$, Olivier Lafon ${ }^{3}$, Julien Trébosc ${ }^{3}$, Kyung Duk Kim$^{1}$, Catherine Stampfl ${ }^{4}$, Alfons Baiker ${ }^{5}$,
} Jean-Paul Amoureux ${ }^{3} \&$ Jun Huang $^{1}$

Zeolites and amorphous silica-alumina (ASA), which both provide Brønsted acid sites (BASs), are the most extensively used solid acid catalysts in the chemical industry. It is widely believed that BASs consist only of tetra-coordinated aluminum sites ( $\mathrm{Al} \mathrm{I}^{\mathrm{V}}$ ) with bridging $\mathrm{OH}$ groups in zeolites or nearby silanols on ASA surfaces. Here we report the direct observation in ASA of a new type of BAS based on penta-coordinated aluminum species (AI ${ }^{V}$ ) by ${ }^{27} \mathrm{Al}-\left\{{ }^{1} \mathrm{H}\right\}$ dipolar-mediated correlation two-dimensional NMR experiments at high magnetic field under magic-angle spinning. Both BAS-AIV and - $\mathrm{Al}^{\vee}$ show a similar acidity to protonate probe molecular ammonia. The quantitative evaluation of ${ }^{1} \mathrm{H}$ and ${ }^{27} \mathrm{Al}$ sites demonstrates that BAS-AI ${ }^{\vee}$ co-exists with BAS-AIV rather than replaces it, which opens new avenues for strongly enhancing the acidity of these popular solid acids.

\footnotetext{
${ }^{1}$ Laboratory for Catalysis Engineering, School of Chemical and Biomolecular Engineering, Sydney University, Chemical Engineering Building J01, Sydney, New South Wales 2006, Australia. ${ }^{2}$ Department of Engineering, Macquarie University, Sydney, New South Wales 2109, Australia. ${ }^{3}$ Univ. Lille, CNRS, UMR 8181-UCCS, Unité de Catalyse et de Chimie du Solide, F-59000 Lille, France. ${ }^{4}$ School of Physics, Sydney University, Sydney, New South Wales 2006, Australia. ${ }^{5}$ Institute for Chemical and Bioengineering, Department of Chemistry and Applied Bioscience, ETH Zürich, Hönggerberg, HCl, CH-8093 Zürich, Switzerland. Correspondence and requests for materials should be addressed to J.H. (email: jun.huang@sydney.edu.au) or to J.-P.A. (email: jean-paul.amoureux@univ-lille1.fr).
} 
T he need for efficient and environmentally benign chemical processes has forced the replacement of harmful and corrosive liquid acids by solid acids in various fields of catalysis, including fine chemistry ${ }^{-3}$, renewable energy production $^{4-6}$, oil refining and petrochemical industries ${ }^{7,8}$. Silicon- and aluminum-based mixed oxides provide moderate and strong Brønsted acidity and are among the most popular solid acids used in current chemical processes ${ }^{7,9}$. Briefly, the solid acid catalysts can protonate hydrocarbon molecules to form carbocations and drive important reactions, such as cracking, hydrocracking, isomerization, alkylation and aromatization ${ }^{10-14}$, through surface complexes or transition states ${ }^{15}$.

Crystalline zeolites and amorphous silica-alumina (ASA) are two main types of solid acids that contain Brønsted acid sites (BASs). It has been widely believed that only tetra-coordinated aluminum $\left(\mathrm{Al}^{\mathrm{IV}}\right)$ atoms are able to contribute to the formation of BASs in nature ${ }^{16}$. In crystalline zeolites, the BASs are formed by protons, which compensate the negatively charged oxygens induced by the substitution of $\mathrm{Si}$ atoms by $\mathrm{Al}^{\mathrm{IV}}$ in the framework. The structure of these sites is well known as the bridging $\mathrm{Si}(\mathrm{OH}) \mathrm{Al}^{\mathrm{IV}}$ model (Fig. 1a) ${ }^{15-17}$. Replacing Si atoms by more $\mathrm{Al}^{\mathrm{IV}}$ species can enhance the density of BASs, but it reduces the mean electronegativity of the framework, which thus leads to a decrease of the overall acid strength of BASs ${ }^{18,19}$. Similarly, $\mathrm{Al}^{\mathrm{IV}}$ species incorporated into the amorphous silica network are able to generate BASs on ASA $9,20,21$. The proximity between $\mathrm{Al}^{\mathrm{IV}}$ and silanol sites in ASA has recently been observed by nuclear magnetic resonance (NMR) correlation experiments between ${ }^{29} \mathrm{Si}$ and ${ }^{27} \mathrm{Al}$ nuclei, the sensitivity of which was enhanced by dynamic nuclear polarization ${ }^{22}$. However, the strength of these BASs is generally lower than that on crystalline zeolites $^{7}$ and thus the presence of bridging $\mathrm{OH}$ groups (Fig. 1a) in ASA is still strongly under debate ${ }^{22,23}$.

A flexible coordination between the $\mathrm{Al}^{\mathrm{IV}}$ atom and the neighbouring silanol oxygen atom (Fig. $1 \mathrm{~b})^{9,21,24,25}$ or a pseudobridging silanol (PBS) with a nearby Al atom (Fig. 1c) (6,22 $^{2}$ have been proposed ${ }^{22}$, to account for the longer $\mathrm{Al}-\mathrm{O}$ distances (2.94-4.43 $\mathrm{A})$ in $\mathrm{ASA}^{26}$, with respect to those in the crystalline zeolite framework $(1.88-2.0 \AA)^{28}$. So far, most efforts focus on tuning the concentration of $\mathrm{Al}^{\mathrm{IV}}$ as the main route to increase the Brønsted acidity on zeolites or silica-alumina ${ }^{29-33}$. However, $\mathrm{Al}^{\mathrm{IV}}$ species tend to condense, to form an alumina phase at high $\mathrm{Al} / \mathrm{Si}$ ratios $^{34-36}$, leading to the decrease of Brønsted acidity. For ASA containing solely BASs based on $\mathrm{Al}^{\mathrm{IV}}$ species (BAS- $\mathrm{Al}^{\mathrm{IV}}$ ), the maximum Brønsted acidity has been obtained at $30 \mathrm{wt} \%$ Al loading 37,38 . In spite of the different BAS models, only $\mathrm{Al}^{\mathrm{IV}}$ species have been experimentally confirmed to contribute to the formation of BASs in these catalysts. $\mathrm{Al}^{\mathrm{V}}$ and $\mathrm{Al}^{\mathrm{VI}}$ species have been shown to act as Lewis acid sites on ASA and zeolites, but, to the best of our knowledge, no experimental evidence of BASs involving these sites has been reported so $\mathrm{far}^{39-42}$.

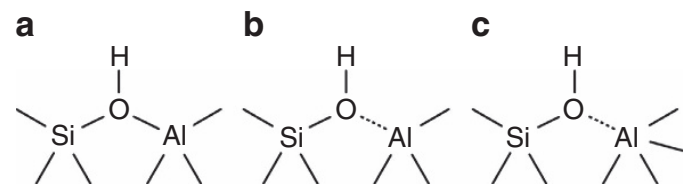

Figure 1 | Proposed models for BASs in silica-alumina catalysts. (a) BAS consisting of a bridging silanol site bonded to $\mathrm{Al}^{\mathrm{IV}}$ site $(\mathrm{Si}(\mathrm{OH}) \mathrm{Al})$ in zeolites $^{15}$. (b) BAS consisting of the flexible coordination between silanol oxygen and neighbouring $\mathrm{Al}^{\mathrm{IV}}$ (ref. 24). (c) BAS consisting of PBS interacting with $\mathrm{Al}^{\mathrm{IV}} \mathrm{site}^{27}$. In that later case, the dotted line does not denote a covalent bond but only the close proximity between $\mathrm{O}$ and $\mathrm{Al}$ atoms.
Herein, we provide the direct experimental evidence for a new type of $\mathrm{BAS}-\mathrm{Al}^{\mathrm{V}}$ in ASA by dipolar-mediated heteronuclear multiple quantum correlation (D-HMQC) two-dimensional (2D) NMR experiments, which allow the detection of protons via ${ }^{27} \mathrm{Al}$ nuclei, hereafter noted ${ }^{27} \mathrm{Al}-\left\{{ }^{1} \mathrm{H}\right\}$, hence probing the spatial proximities between different $\mathrm{Al}$ species and surface protons ${ }^{43-45}$. These experiments show that ASA can contain a large amount of $\mathrm{Al}^{\mathrm{V}}$ species located near $\mathrm{SiOH}$ groups. The acidity of these surface BAS- $\mathrm{Al}^{\mathrm{V}}$ sites has been demonstrated in this research by the adsorption of basic ammonia molecules, which react with $\mathrm{BAS}-\mathrm{Al}^{\mathrm{V}}$ to form surface ammonium ions.

\section{Results}

Probing the connectivity between $\mathrm{Al}^{\mathrm{V}}$ species and $\mathrm{SiOH}$ groups. The ASAs used in this work (see Supplementary Methods) have been prepared according to a previously described procedure $^{9}$, which generates ASA nanoparticles with a large amount of $\mathrm{Al}^{\mathrm{V}}$ species. The ASA powders are designated as $\mathrm{SA} / X$, where $X$ is 10 or 50 , indicating the molar fraction of $\mathrm{Al}$ in the precursor with respect to the total amount of $\mathrm{Al}$ and $\mathrm{Si}$ atoms. The obtained ASAs have tunable BAS acidity strengths ranging from moderate (SA/10 has an acidity close to zeolite $\mathrm{H}-\mathrm{X}$ ) to large (SA/30-70 have stronger BASs than zeolites H-Y and ZSM-5), depending on the aluminum content, as confirmed by both ${ }^{13} \mathrm{C}$ magic angle spinning (MAS) NMR investigation with probe molecule acetone and ammonia-temperature program desorption (TPD) $)^{9}$. The ASAs exhibited excellent catalytic performances for the conversion of phenylglyoxal with various alcohols, better than that of dealuminated zeolite $\mathrm{Y}$, which hitherto was considered to be the most active solid acid in phenylglyoxal conversion ${ }^{2}$.

The formation of BAS requires the aluminum atoms to be close to $\mathrm{SiOH}$ groups. Such proximity induces a dipolar coupling between ${ }^{27} \mathrm{Al}$ and ${ }^{1} \mathrm{H}$ nuclei, which can efficiently be probed by $D$-HMQC NMR 2 D experiments based on coherence transfers via the ${ }^{1} \mathrm{H}^{-27} \mathrm{Al}$ dipolar couplings ${ }^{46,47}$. As shown in Fig. 2, the correlation at $\delta_{27 \mathrm{~A}}=50$ p.p.m. and $\delta_{1 \mathrm{H}}=1.9$ p.p.m. in the ${ }^{27} \mathrm{Al}-\left\{{ }^{1} \mathrm{H}\right\} D$-HMQC $2 \mathrm{D}$ spectrum of dehydrated SA/50 indicates a close proximity between $\mathrm{Al}^{\mathrm{IV}}$ species and the proton of $\mathrm{SiOH}$ groups. This correlation is ascribed to the $\mathrm{Si}-\mathrm{OH} \cdots \mathrm{Al}^{\mathrm{IV}}$ coordination: the typical BAS- $\mathrm{Al}^{\mathrm{IV}}$ often described for ASA (Fig. 1c) ${ }^{16}$. A very weak correlation at $\delta_{27 \mathrm{Al}}=10$ p.p.m. and $\delta_{1 \mathrm{H}}=1.1$ p.p.m. is assigned to the non-acidic terminal $\mathrm{Al}^{\mathrm{VI}} \mathrm{OH}$ groups often observed on the surface of silica-alumina or zeolites, whereas the low-field broad hump at ca. 6p.p.m. in the

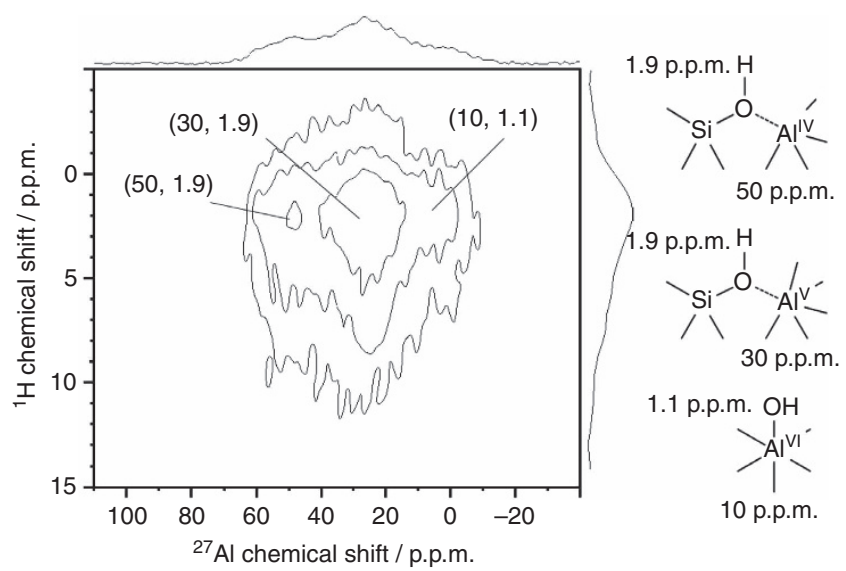

Figure $\left.2\right|^{\mathbf{2 7}} \mathbf{A l}-\left\{{ }^{\mathbf{1}} \mathbf{H}\right\}$ D-HMQC $2 \mathrm{D}$ spectrum of SA/50. The sample was dehydrated at $723 \mathrm{~K}$ for $12 \mathrm{~h}$ under vacuum and recorded at $18.8 \mathrm{~T}$ with a MAS frequency of $v_{\mathrm{R}}=20 \mathrm{kHz}$ and $\tau_{\text {rec }}=1.0 \mathrm{~ms}$. The spectrum reveals that the proximity between $\mathrm{SiOH}$ groups and $\mathrm{Al}^{\vee}$ species is dominant. 
${ }^{1} \mathrm{H}$ dimension could be caused by the small fraction of hydrogenbonded $\mathrm{AlOH}$ groups $^{16}$. Nevertheless, the most intense correlation is observed between $\mathrm{Al}^{\mathrm{V}}$ species $\left(\delta_{27 \mathrm{~A}}=30\right.$ p.p.m. $)$ and $\mathrm{SiOH}$ protons $\left(\delta_{1 \mathrm{H}}=1.9\right.$ p.p.m.), which indicates the close proximity between $\mathrm{SiOH}$ groups and $\mathrm{Al}^{\mathrm{V}}$ species, and the presence of $\mathrm{Si}-\mathrm{OH} \cdots \mathrm{Al}^{\mathrm{V}}$ coordination (Fig. 2) in dehydrated SA/50.

$\mathbf{A l}^{\mathrm{V}}$-based BASs. In zeolites, the substitution of a framework $\mathrm{Si}$ atom by an $\mathrm{Al}^{\mathrm{IV}}$ one to form one SiOHAl acid site (Fig. 1a) can shift the ${ }^{1} \mathrm{H}$ NMR signal of $\mathrm{SiOH}$ from ca. 1.8 to 3.6-5.2 p.p.m. (ref. 16). For these catalysts, BAS could be directly evidenced by the cross-peak in ${ }^{27} \mathrm{Al}-\left\{{ }^{1} \mathrm{H}\right\} \quad D$-HMQC $2 \mathrm{D}$ spectrum between $\mathrm{Al}^{\mathrm{IV}}$ species $\left(\delta_{27 \mathrm{Al}}=60\right.$ p.p.m. $)$ and the bridging $\mathrm{OH}$ groups $\left(\delta_{1 \mathrm{H}}=4.3 \text { p.p.m. }\right)^{43}$. However, previous works have shown that the $\mathrm{Al}$ atoms with neighbouring $\mathrm{SiOH}$ groups (Fig. 1b,c) do not produce such a shift of the ${ }^{1} \mathrm{H}$ MAS signal of these groups $5,6,9,16,20,21$. Supplementary Fig. 1a,b show that the ${ }^{\mathrm{P}}$ signal of $\mathrm{SA} / 10$ and $\mathrm{SA} / 50$ is centred around 1.9 p.p.m., thus indicating a majority of flexible or PBS coordination rather than zeolitic bridging coordination between $\mathrm{SiOH}$ groups and either $\mathrm{Al}^{\mathrm{IV}}$ or $\mathrm{Al}^{\mathrm{P}}$ species.

Experiments using probe molecules have confirmed the role of flexible or $\mathrm{PBS}$ Si-OH $\cdots \mathrm{Al}^{\mathrm{IV}}$ coordination as BAS in $\mathrm{ASA}^{5,6,9,16,20,21}$. Similar methods using ammonia probe molecules were applied here to demonstrate the acidity of the $\mathrm{Si}-\mathrm{OH} \cdots \mathrm{Al}^{\mathrm{V}}$ coordination observed in dehydrated $\mathrm{SA} / 10$ and $\mathrm{SA} / 50$ (ref. 16). For these samples loaded with ammonia, the ${ }^{1} \mathrm{H}$ signal of ammonium ions was observed at $\delta_{1 \mathrm{H}}=6.7$ p.p.m., as shown in Supplementary Fig. 1c,d, and commented in Supplementary Note 1 . The formation of these ions shows that ammonia reacts with BAS of SA/10 and SA/50.

${ }^{27} \mathrm{Al}-\left\{{ }^{1} \mathrm{H}\right\} \quad D$-HMQC experiments were also carried out to determine the nature of BAS, which protonate the ammonia molecules. Such a strategy based on ${ }^{1} \mathrm{H}_{-}{ }^{27} \mathrm{Al}$ correlations has been applied for [Al]MCM-41 loaded with ammonia. For such catalysts, ammonium ions $\left(\delta_{1 \mathrm{H}}=6.7\right.$ p.p.m. $)$ were only coupled to $\mathrm{Al}^{\mathrm{IV}}$ species $\left(\delta_{27 \mathrm{~A}}=56 \text { p.p.m. }\right)^{44}$. Hence, there was only evidence for BAS-Al ${ }^{\mathrm{IV}}$ on the surface of [Al]MCM-41, which protonated ammonia to ammonium ions. As seen in Fig. 3, a correlation between $\mathrm{NH}_{4}^{+}$ions $\left(\delta_{1 \mathrm{H}}=6.7\right.$ p.p.m. $)$ and $\mathrm{Al}^{\mathrm{IV}}\left(\delta_{27 \mathrm{Al}}=50\right.$ p.p.m. $)$ is also observed in ${ }^{27} \mathrm{Al}-\left\{{ }^{1} \mathrm{H}\right\} D$-HMQC spectra of SA/10 and SA/50, showing that the BAS-Al ${ }^{\mathrm{IV}}$ sites are also present on the surface of ASAs (Fig. 4a). Interestingly, these spectra also exhibit cross-peaks between $\mathrm{Al}^{\mathrm{V}}$ species $\left(\delta_{27 \mathrm{Al}}=30\right.$ p.p.m. $)$ and $\mathrm{NH}_{4}^{+}$ions $\left(\delta_{1 \mathrm{H}}=6.7\right.$ p.p.m. $)$ in both $\mathrm{SA} / 10$ and $\mathrm{SA} / 50$. As seen in Fig. 3e, the intensity of this $\mathrm{Al}^{\mathrm{V}}-\mathrm{NH}_{4}^{+}$cross-peak is comparable to that of the $\mathrm{Al}^{\mathrm{IV}}-\mathrm{NH}_{4}^{+}$ one. Given the BAS density ranging from 0.16 to $0.36 \mathrm{H}^{+} \mathrm{nm}^{-2}$ in the investigated ASA samples (Supplementary Table 1), each ammonia molecule only interacts with one BAS. The distance between the aluminum atom and the neighbouring silanol oxygen in ASA ranges from $c a .2 .94$ to $4.43 \AA^{26}$ and the $\mathrm{N}-\mathrm{H}$ bond length in ammonia is only $1.02 \AA^{48}$. As the heteronuclear coherence transfer in ${ }^{27} \mathrm{Al}-\left\{{ }^{1} \mathrm{H}\right\} \quad D$-HMQC is only effective up to a few angstroms, the protons of $\mathrm{Si}-\mathrm{O}^{-}\left(\mathrm{NH}_{4}\right)^{+} \ldots \mathrm{Al}$ environment only interact with the neighbouring $\mathrm{Al}$. The observation of an $\mathrm{Al}^{V}-\mathrm{NH}_{4}^{+}$cross-peak in Fig. 3 at $(30,6.7)$ p.p.m. directly confirmed that ammonia is protonated on a BAS containing $\mathrm{Al}^{\mathrm{V}}$ : the $\mathrm{Si}-\mathrm{OH} \cdots \mathrm{Al}^{\mathrm{V}}$ group.

The comparison of Supplementary Fig. 1c,d shows that more ammonia molecules are protonated on $\mathrm{BAS}-\mathrm{Al}^{\mathrm{V}}$ in $\mathrm{SA} / 50$ than in $\mathrm{SA} / 10$. Combined with quantitative ${ }^{1} \mathrm{H}$ NMR investigations (Supplementary Fig. 1) and the quadrupolar parameters (Supplementary Table 2 and Supplementary Note 2) obtained
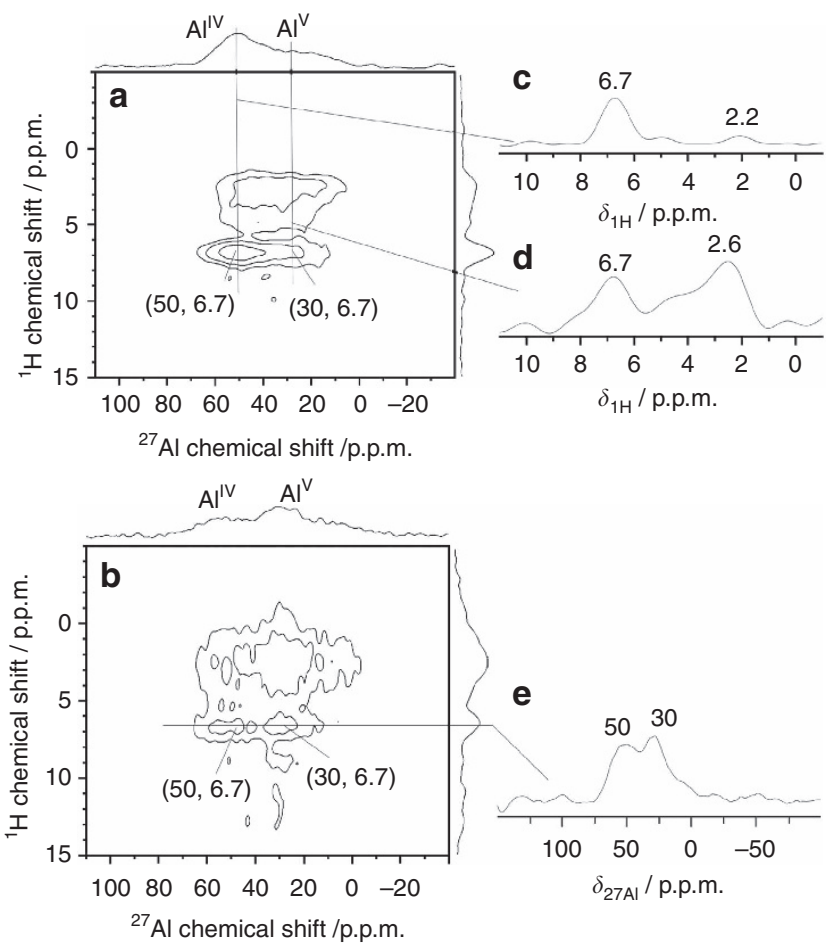

Figure $\left.3\right|^{27}$ Al- $\left\{{ }^{1} H\right\}$ D-HMQC 2D spectra of ammonia-loaded ASA

samples. The dehydrated $\mathrm{SA} / 10$ (a) and $\mathrm{SA} / 50$ (b) samples were loaded with ammonia and evacuated at $373 \mathrm{~K}$ for $1 \mathrm{~h}$, and the spectra were recorded at $18.8 \mathrm{~T}$ with $v_{\mathrm{R}}=20 \mathrm{kHz}$ and $\tau_{\text {rec }}=900 \mu \mathrm{s}$. The ${ }^{1} \mathrm{H}$ slices at the shifts of $\mathrm{Al}^{\mathrm{IV}}$ and $\mathrm{Al}^{\mathrm{V}}$ sites of $\mathrm{SA} / 10$ extracted from the 2D spectrum (a) are displayed in subfigures $(\mathbf{c}, \mathbf{d})$, respectively. The subfigure (e) shows the ${ }^{27} \mathrm{Al}$ slice at the shift of $\mathrm{NH}_{4}^{+}$protons in $\mathrm{SA} / 50$ extracted from the spectrum (b).

a 1.9 p.p.m 6.7 p.p.m

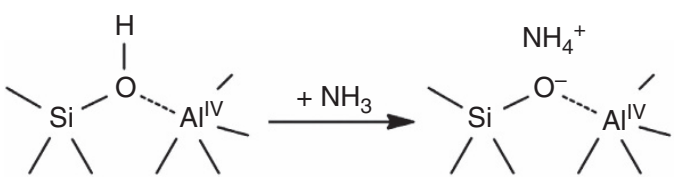

b

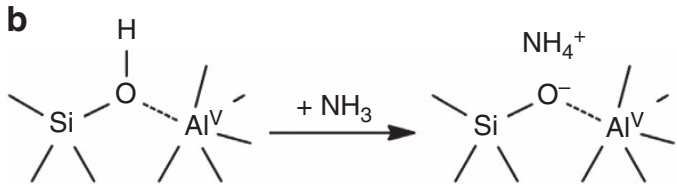

Figure 4 | Proposed proton transfer between BAS and ammonia molecules. (a) Ammonia protonated on conventional acidic BAS-AI ${ }^{\mathrm{IV}}$. (b) BAS-AV $V^{V}$ formed on ASA is able to transfer hydroxyl proton to ammonia, showing similar acidic properties as BAS-AIIV.

from ${ }^{27} \mathrm{Al}$ one-dimensional MAS (Supplementary Fig. 3) and 2D multiple quantum MAS (Supplementary Fig. 2) NMR experiments, the analysis of ${ }^{27} \mathrm{Al}$ cross-peak intensities in ${ }^{27} \mathrm{Al}-\left\{{ }^{1} \mathrm{H}\right\} \quad D$-HMQC spectra (Supplementary Fig. 4 and Supplementary Note 3 ) revealed that the population densities of both BAS- $\mathrm{Al}^{\mathrm{IV}}$ and $-\mathrm{Al}^{\mathrm{V}}$ on SA/50 $\left(0.078\right.$ and $\left.0.053 \mathrm{mmolg}^{-1}\right)$ were both higher than those of SA/10 $(0.058$ and $\left.0.039 \mathrm{mmolg}{ }^{-1}\right)$. This result suggests that BAS- $\mathrm{Al}^{\mathrm{IV}}$ and $-\mathrm{Al}^{\mathrm{V}}$ can co-exist on the surface rather than replacing each other and the population of both acid sites can be amplified by increasing $\mathrm{Al}$ content. Thus, this observation is promising for enhancing the population of BAS on ASA without limitation imposed by the $\mathrm{Al}$ 
contents. It should be noted that the $\mathbf{F}_{2}$ projections of ${ }^{27} \mathrm{Al}-\left\{{ }^{1} \mathrm{H}\right\}$ $D$-HMQC 2D spectra are almost identical for dehydrated and ammonia-loaded SA/50 (see Supplementary Fig. 5 and Supplementary Note 4). Therefore, $\mathrm{Si}-\mathrm{OH} \cdots \mathrm{Al}^{\mathrm{V}}$ and $\mathrm{Si}-\mathrm{OH} \cdots \mathrm{Al}{ }^{\mathrm{IV}}$ coordinations remained unchanged after the protonation of ammonia (as shown in Fig. 4). No Si-OH $\cdots \mathrm{Al}^{\mathrm{IV}}$ have been transferred to $\mathrm{Si}-\mathrm{OH}-\mathrm{Al}^{\mathrm{V}}$ permanently after the adsorption of ammonia. In other words, the NMR results do not show the formation of permanent covalent bridges between silicate and $\mathrm{Al}^{\mathrm{IV}}$ or $\mathrm{Al}^{\mathrm{V}}$ sites in ASA samples after the deprotonation of BAS reacting with ammonia. Ammonia partially interacting with surface $\mathrm{Al}^{\mathrm{IV}}$ or $\mathrm{Al}^{\mathrm{V}}$ sites (Fig. 3b and Supplementary Fig. 6) was also observed, which has been assigned to ammonia adsorbed on Lewis sites (Supplementary Note 5).

As shown in Fig. 1, a surface bridging SiOHAl (Fig. 1a), a flexible coordination of $\mathrm{SiOH}$ and $\mathrm{Al}$ (Fig. 1b), or a pseudo-bridge between $\mathrm{SiOH}$ and $\mathrm{Al}$ atom (Fig. 1c) have been proposed for the formation of $\mathrm{BAS}-\mathrm{Al}^{\mathrm{IV}}$ on ASAs. By analogy, similar structures might also contribute to the formation of $\mathrm{BAS}-\mathrm{Al}^{\mathrm{V}}$. The PBS model permits an explanation of the observation of the ${ }^{1} \mathrm{H}$ NMR signal of $\mathrm{SiOH}$ at 1.9 p.p.m. in both Fig. 2 and Supplementary Fig. 1, whereas this ${ }^{1} \mathrm{H}$ signal of bridging $\mathrm{OH}$ groups (Fig. 1a) should occur at 3.6-5.2 p.p.m. If bridging $\mathrm{OH}$ groups are present in the investigated ASAs, their concentration must be below the limit of detection of the one-dimensional NMR MAS spectra of Supplementary Fig. 1. Nevertheless, the current NMR data cannot rule out, in addition to PBS, the presence of bridging silanol groups in low concentration in ASA samples. These elusive strong BASs may also contribute to the catalytic activity in spite of their low concentration. The identification of all catalytic BASs in ASAs is beyond the scope of the present study, which is mainly to report the existence of BASs based on $\mathrm{Al}^{\mathrm{V}}$ environments. A final assessment of the local structure of BAS- $\mathrm{Al}^{\mathrm{V}}$ will require further experimental and theoretical work.

In summary, a new type of BAS-Al ${ }^{\mathrm{V}}$ has been directly observed by ${ }^{27} \mathrm{Al}-\left\{{ }^{1} \mathrm{H}\right\}$ D-HMQC NMR spectroscopy. Hitherto, it was widely accepted that $\mathrm{Al}^{\mathrm{V}}$ sites only provide Lewis acidity ${ }^{39-42}$, and that solely $\mathrm{Al}^{\mathrm{IV}}$ ones contribute to the formation of BASs in aluminosilicate. However, we prove here by NMR experiments that similar to $\mathrm{Al}^{\mathrm{IV}}$ sites, $\mathrm{Al}^{\mathrm{V}}$ ones interact with neighbouring $\mathrm{SiOH}$ groups in ASA and behave as BASs in agreement with the $\mathrm{PBS}$ model. BAS-Al ${ }^{\mathrm{IV}}$ and $-\mathrm{Al}^{\mathrm{V}}$ seem to be structurally similar and show comparable acidity to protonate ammonia. Finally, a very important implication emerging from this work is that both $\mathrm{Al}^{\mathrm{IV}}$ and $\mathrm{Al}^{\mathrm{V}}$ species can co-exist on the surface of ASA. This feature facilitates that the total population density of BAS can be increased up to $70 \%$ by increasing the $\mathrm{Al}$ content, an amount much higher than the maximum Al loading of $c a .30 \%$ at which maximum acidity on ASA containing exclusively $\mathrm{BAS}-\mathrm{Al}^{\mathrm{IV}}$ is achieved $^{37,38}$. Hence, our findings not only report the existence of a new type of BAS in nature, but also open new avenues for creating high-performance solid acid catalysts containing $\mathrm{Al}^{\mathrm{V}}$ species, which will be promising for sustainable oil-refining and many industrial chemical processes.

\footnotetext{
Methods

${ }^{27} \mathbf{A l}-\left\{{ }^{\mathbf{1}} \mathbf{H}\right\}$ D-HMQC 2D experiment. All NMR experiments were recorded on a Bruker Avance III $18.8 \mathrm{~T}\left({ }^{1} \mathrm{H}\right.$ Larmor frequency of $\left.800 \mathrm{MHz}\right)$ spectrometer equipped with a $3.2 \mathrm{~mm}$ double-resonance MAS probe, in which rotors were spun at $v_{\mathrm{R}}=20 \mathrm{kHz}$. In the $D$-HMQC sequence, we have detected the ${ }^{27} \mathrm{Al}$ nuclei to benefit from their fast longitudinal relaxation times and the ${ }^{1} \mathrm{H}^{2}{ }^{27} \mathrm{Al}$ dipolar couplings were reintroduced by applying a SR $4{ }_{1}^{2}$ recoupling on the ${ }^{1} \mathrm{H}$ channel $^{49}$. The ${ }^{1} \mathrm{H}$ radiofrequency amplitudes for the $90^{\circ}$ pulses and the $\mathrm{SR} 4_{1}^{2}$ recoupling were equal to $v_{1}=62.5$ and $40 \mathrm{kHz}$, respectively. The central transition selective pulse lengths on ${ }^{27} \mathrm{Al}$ were 8 and $16 \mu$ s for $90^{\circ}$ and $180^{\circ}$ pulses, respectively, that is, radiofrequency field amplitude $v_{1}=10 \mathrm{kHz}$. The total dipolar recoupling time, $\tau_{\text {rec }}$, ranged from 700 to $1,000 \mu$ s depending on the
}

sample. The $2 \mathrm{D}$ spectra resulted from the accumulation of 512 transients for each of $20 t_{1}$ increments with $\Delta t_{1}=50 \mu \mathrm{s}$ and a recycle delay $=1 \mathrm{~s}$, that is, a total experiment time of about $3 \mathrm{~h}$. Additional details about NMR experiments are given in the Supplementary Methods.

Data availability. The data that support the findings of this study are available upon request from the corresponding author J.H. and J.-P.A

\section{References}

1. Corma, A., Iborra, S. \& Velty, A. Chemical routes for the transformation of biomass into chemicals. Chem. Rev. 107, 2411-2502 (2007).

2. Wang, Z., Jiang, Y., Baiker, A. \& Huang, J. Efficient acid-catalyzed conversion of phenylglyoxal to mandelates on flame-derived silica/alumina. ACS Catal 3, 1573-1577 (2013).

3. Wang, Z., Jiang, Y., Hunger, M., Baiker, A. \& Huang, J. Catalytic performance of Brønsted and Lewis acid sites in phenylglyoxal conversion on flame-derived silica-zirconia. ChemCatChem 6, 2970-2975 (2014).

4. Huber, G. W., Iborra, S. \& Corma, A. Synthesis of transportation fuels from biomass: chemistry, catalysts, and engineering. Chem. Rev. 106, 4044-4098 (2006).

5. Huang, J., Jiang, Y., van Vegten, N., Hunger, M. \& Baiker, A. Tuning the support acidity of flame-made $\mathrm{Pd} / \mathrm{SiO}_{2}-\mathrm{Al}_{2} \mathrm{O}_{3}$ catalysts for chemoselective hydrogenation. J. Catal. 281, 352-360 (2011).

6. Wang, Z. et al. Palladium-doped silica-alumina catalysts obtained from double-flame FSP for chemoselective hydrogenation of the model aromatic ketone acetophenone. J. Catal. 302, 10-19 (2013).

7. Corma, A. Inorganic solid acids and their use in acid-catalyzed hydrocarbon reactions. Chem. Rev. 95, 559-614 (1995).

8. Busca, G. Acid catalysts in industrial hydrocarbon chemistry. Chem. Rev. 107, 5366-5410 (2007).

9. Huang, J., van Vegten, N., Jiang, Y., Hunger, M. \& Baiker, A. Increasing the Brønsted acidity of flame-derived silica/alumina up to zeolitic strength. Angew. Chem. Int. Ed. 49, 7776-7781 (2010).

10. Engelhardt, J. \& Hall, W. K. Peculiarities observed in H-D exchange between perdeuterioisobutane and H-zeolites. J. Catal. 151, 1-9 (1995).

11. Hua, W. et al. H/D exchange reaction between isobutane and acidic USY zeolite: a mechanistic study by mass spectrometry and in situ NMR. J. Catal. 204, 460-465 (2001).

12. Olah, G. A. Carbocations and electrophilic reactions. Angew. Chem. Int. Ed. 12, 173-212 (1973).

13. Olah, G. A. Friedel-Crafts Chemistry (Wiley-Interscience, 1973)

14. Olah, G. A. My search for carbocations and their role in chemistry (Nobel lecture). Angew. Chem. Int. Ed. 34, 1393-1405 (1995).

15. Weitkamp, J. \& Hunger, M. in Studies in Surface Science and Catalysis (eds Ejka, J., van Bekkum, H., Corma, A. \& Schüth, F.) 787-835 (Elsevier, 2007).

16. Jiang, Y., Huang, J., Dai, W. \& Hunger, M. Solid-state nuclear magnetic resonance investigations of the nature, property, and activity of acid sites on solid catalysts. Solid State Nucl. Magn. Reson. 39, 116-141 (2011).

17. Li, S. et al. Brønsted/Lewis acid synergy in dealuminated HY zeolite: a combined solid-state NMR and theoretical calculation study. J. Am. Chem. Soc 129, 11161-11171 (2007).

18. Jacobs, P. A., Mortier, W. J. \& Uytterhoeven, J. B. Properties of zeolites in relation to their electronegativity - acidity, carboniogenic activity and strength of interaction in transition-metal complexes. J. Inorg. Nucl. Chem. 40, 1919-1923 (1978).

19. Mortier, W. J. Zeolite electronegativity related to physicochemical properties. J. Catal. 55, 138-145 (1978).

20. Wang, Z. et al. One-step room-temperature synthesis of Al MCM-41 materials for the catalytic conversion of phenylglyoxal to ethylmandelate. ChemCatChem 5, 3889-3896 (2013).

21. Luo, Q. et al. Using trimethylphosphine as a probe molecule to study the acid states in Al-MCM-41 materials by solid-state NMR spectroscopy. J. Phys. Chem. B 107, 2435-2442 (2003).

22. Valla, M. et al. Atomic description of the interface between silica and alumina in aluminosilicates through dynamic nuclear polarization surface-enhanced nmr spectroscopy and first-principles calculations. J. Am. Chem. Soc. 137, 10710-10719 (2015).

23. Hensen, E. J. M. et al. Acidity characterization of amorphous silica-alumina. J. Phys. Chem. C 116, 21416-21429 (2012).

24. Omegna, A., van Bokhoven, J. A. \& Prins, R. Flexible aluminum coordination in alumino-silicates. Structure of zeolite H-USY and amorphous silica-alumina. J. Phys. Chem. B 107, 8854-8860 (2003).

25. Hunger, M., Schenk, U., Breuninger, M., Glaser, R. \& Weitkamp, J. Characterization of the acid sites in MCM-41-type materials by spectroscopic and catalytic techniques. Micro. Meso. Mater. 27, 261-271 (1999). 
26. Chizallet, C. \& Raybaud, P. Pseudo-bridging silanols as versatile Brønsted acid sites of amorphous aluminosilicate surfaces. Angew. Chem. Int. Ed. 48, 2891-2893 (2009).

27. Chizallet, C. \& Raybaud, P. Acidity of Amorphous silica-alumina: from coordination promotion of Lewis sites to proton transfer. ChemPhysChem 11, 105-108 (2010)

28. Eichler, U., Brandle, M. \& Sauer, J. Predicting absolute and site specific acidities for zeolite catalysts by a combined quantum mechanics interatomic potential function approach. J. Phys. Chem. B 101, 10035-10050 (1997).

29. Dewitte, B. M., Grobet, P. J. \& Uytterhoeven, J. B. Pentacoordinated aluminum in noncalcined amorphous aluminosilicates, prepared in alkaline and acidmedium. J. Phys. Chem. 99, 6961-6965 (1995).

30. Williams, M. F. et al. Hydrogenation of tetralin on silica-alumina-supported Pt catalysts I. Physicochemical characterization of the catalytic materials. J. Catal. 251, 485-496 (2007).

31. de Boer, J. H. Constitution and properties of silica-alumina-catalysts. Discuss. Farad. Soc. 52, 109-112 (1971).

32. Haag, W. O., Lago, R. M. \& Weisz, P. B. The active site of acidic aluminosilicate catalysts. Nature 309, 589-591 (1984).

33. Xu, B. et al. Strong Brønsted acidity in amorphous silica - aluminas. J. Phys. Chem. C 111, 12075-12079 (2007).

34. Matsumoto, A., Chen, H., Tsutsumi, K., Grun, M. \& Unger, K. Novel route in the synthesis of MCM-41 containing framework aluminum and its characterization. Micro. Meso. Mater. 32, 55-62 (1999).

35. Eimer, G. A., Pierella, L. B., Monti, G. A. \& Anunziata, O. A. Synthesis and characterization of Al-MCM-41 and Al-MCM-48 mesoporous materials. Catal. Lett. 78, 65-75 (2002).

36. Hensen, E. et al. Formation of acid sites in amorphous silica-alumina. J. Catal. 269, 201-218 (2010).

37. Tanabe, K. Solid Acids and Bases and Their Catalytic Properties (Academic Press, 1970).

38. Hunger, M. et al. High-resolution proton magnetic-resonance and catalytic studies concerning Brønsted centers of amorphous $\mathrm{Al}_{2} \mathrm{O}_{3}-\mathrm{SiO}_{2}$ solids. Chem. Phys. Lett. 100, 29-33 (1983).

39. Coster, D., Blumenfeld, A. L. \& Fripiat, J. J. Lewis acid sites and surface aluminum in aluminas and zeolites: a high-resolution NMR study. J. Phys. Chem. 98, 6201-6211 (1994).

40. Ma, D. et al. An investigation of the roles of surface aluminum and acid sites in the zeolite MCM-22. Chem. Eur. J. 8, 162-170 (2002).

41. Borade, R., Adnot, A. \& Kaliaguine, S. An XPS study of acid sites in dehydroxylated Y zeolites. J. Mol. Catal. 61, L7-L14 (1990).

42. Kwak, J. H., Mei, D., Peden, C. H. F., Rousseau, R. \& Szanyi, J. (100) facets of gamma- $\mathrm{Al}_{2} \mathrm{O}_{3}$ : the active surfaces for alcohol dehydration reactions. Catal. Lett. 141, 649-655 (2011).

43. Li, S. et al. Extra-framework aluminium species in hydrated faujasite zeolite as investigated by two-dimensional solid-state NMR spectroscopy and theoretical calculations. Phys. Chem. Chem. Phys. 12, 3895-3903 (2010).

44. Janicke, M. T. et al. Aluminum incorporation and interfacial structures in MCM-41 mesoporous molecular sieves. J. Am. Chem. Soc. 120, 6940-6951 (1998).

45. Wang, Y. Y., Mu, Y., Sun, Y. J. \& Li, J. Y. Two new four-connected zeolite-like magnesium aluminophosphates with intersecting 8-ring channels. RSC Adv. 4, 56288-56293 (2014)

46. Lafon, O. et al. Indirect detection via spin-1/2 nuclei in solid state NMR spectroscopy: application to the observation of proximities between protons and quadrupolar nuclei. J. Phys. Chem. A. 113, 12864-12878 (2009).
47. Tricot, G. et al. Structural characterisation of phosphate materials: new insights into the spatial proximities between phosphorus and quadrupolar nuclei using the D-HMQC MAS NMR technique. Phys. Chem. Chem. Phys. 13, 16786-16794 (2011).

48. Haynes, W. M. in Handbook of Chemistry and Physics (ed. Ohio) 96 (CRC Press, 2015).

49. Brinkmann, A. \& Kentgens, A. P. M. Proton-selective ${ }^{17} \mathrm{O}-{ }^{1} \mathrm{H}$ distance measurements in fast magic-angle-spinning solid-state NMR spectroscopy for the determination of hydrogen bond lengths. J. Am. Chem. Soc. 128, 14758-14759 (2006).

\section{Acknowledgements}

J.H. and C.S. acknowledge the financial supports from Australian Research Council Discovery Projects (DP150103842). J.H. thanks Faculty's Energy and Materials Clusters and MCR scheme, and the International Project Development Funding at the University of Sydney. O.L., J.L. and J.-P.A. are grateful for funding provided by the Region Nord/Pas de Calais (France), Europe (FEDER), CNRS, Ministère de l'Enseignement Supérieur et de la Recherche, CPER, Chevreul Institute (FR 2638), Infrastructure de Recherche en Eésonance Magnétique Nucléaire à Très Haut Champ (IR-RMN, FR 3050), ENSCL, the University of Lille and contract ANR-14-CE07-0009.

\section{Author contributions}

J.H., Y.J. and C.S. designed the study. Y.J. and A.B. prepared the samples. Z.W., O.L., J.T and J.H. performed the NMR experiments and structural assignation. J.H. and J.-P.A. supervised the scientific work. J.H. and Z.W. contributed to writing the paper, and O.L., J.-P.A., A.B. and C.S. revised it.

\section{Additional information}

Supplementary Information accompanies this paper at http://www.nature.com/ naturecommunications

Competing financial interests: The authors declare no competing financial interests.

Reprints and permission information is available online at http://npg.nature.com/ reprintsandpermissions/

How to cite this article: Wang, Z. et al. Brønsted acid sites based on penta-coordinated aluminum species. Nat. Commun. 7, 13820 doi: 10.1038/ncomms13820 (2016).

Publisher's note: Springer Nature remains neutral with regard to jurisdictional claims in published maps and institutional affiliations.

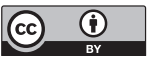

This work is licensed under a Creative Commons Attribution 4.0 International License. The images or other third party material in this article are included in the article's Creative Commons license, unless indicated otherwise in the credit line; if the material is not included under the Creative Commons license, users will need to obtain permission from the license holder to reproduce the material. To view a copy of this license, visit http://creativecommons.org/licenses/by/4.0/

(C) The Author(s) 2016 